\title{
BMJ Open Evaluation of patient characteristics, management and outcomes for COVID-19 at district hospitals in the Western Cape, South Africa: descriptive observational study
}

Robert James Mash (i) , ${ }^{1}$ Mellisa Presence-Vollenhoven, ${ }^{1,2}$ Adeloye Adeniji, ${ }^{1,3}$ Renaldo Christoffels, ${ }^{4,2}$ Karlien Doubell, ${ }^{1,3}$ Lawson Eksteen, ${ }^{1,3}$ Amee Hendrikse, ${ }^{2}$ Lauren Hutton, ${ }^{1,3}$ Louis Jenkins, ${ }^{1,3}$ Paul Kapp, ${ }^{1,3}$ Annie Lombard, ${ }^{1,2}$ Heleen Marais, ${ }^{2}$ Liezel Rossouw, ${ }^{4,2}$ Katrin Stuve, ${ }^{5,2}$ Abi Ugoagwu, ${ }^{4,2}$ Beverley Williams ${ }^{1,3}$

To cite: Mash RJ, PresenceVollenhoven M, Adeniji A, et al. Evaluation of patient characteristics, management and outcomes for COVID-19 at district hospitals in the Western Cape, South Africa: descriptive observational study. BMJ Open 2021;11:e047016. doi:10.1136/ bmjopen-2020-047016

- Prepublication history for this paper is available online. To view these files, please visit the journal online (http://dx.doi. org/10.1136/bmjopen-2020047016).

Received 16 November 2020 Revised 29 December 2020 Accepted 08 January 2021
Check for updates

(c) Author(s) (or their employer(s)) 2021. Re-use permitted under CC BY-NC. No commercial re-use. See rights and permissions. Published by BMJ.

For numbered affiliations see end of article.

Correspondence to

Professor Robert James Mash; rm@sun.ac.za

\section{ABSTRACT}

Objectives To describe the characteristics, clinical management and outcomes of patients with COVID-19 at district hospitals.

Design A descriptive observational cross-sectional study. Setting District hospitals (4 in metro and 4 in rural health services) in the Western Cape, South Africa. District hospitals were small ( $<150$ beds) and led by family physicians.

Participants All patients who presented to the hospitals' emergency centre and who tested positive for COVID-19 between March and June 2020.

Primary and secondary outcome measures Source of referral, presenting symptoms, demographics, comorbidities, clinical assessment and management, laboratory turnaround time, clinical outcomes, factors related to mortality, length of stay and location.

Results 1376 patients (73.9\% metro, $26.1 \%$ rural). Mean age 46.3 years (SD 16.3), 58.5\% females. The majority were self-referred $(71 \%)$ and had comorbidities $(67 \%)$ : hypertension (41\%), type 2 diabetes (25\%), HIV (14\%) and overweight/obesity (19\%). Assessment of COVID-19 was mild $(49 \%)$, moderate $(18 \%)$ and severe $(24 \%)$. Test turnaround time (median 3.0 days (IQR 2.0-5.0 days)) was longer than length of stay (median 2.0 day (IQR 2.0-3.0)). The most common treatment was oxygen (41\%) and only $0.8 \%$ were intubated and ventilated. Overall mortality was $11 \%$. Most were discharged home $(60 \%)$ and only $9 \%$ transferred to higher levels of care. Increasing age (OR 1.06 (95\% Cl 1.04 to 1.07)), male (OR 2.02 (95\% Cl 1.37 to 2.98$)$ ), overweight/obesity (OR $1.58(95 \% \mathrm{Cl} 1.02$ to 2.46)), type 2 diabetes (OR 1.84 (95\% Cl 1.24 to 2.73$)$ ), HIV (OR 3.41 (95\% Cl 2.06 to 5.65)), chronic kidney disease (OR $5.16(95 \% \mathrm{Cl} 2.82$ to 9.43)) were significantly linked with mortality $(p<0.05)$. Pulmonary diseases (tuberculosis (TB), asthma, chronic obstructive pulmonary disease, post-TB structural lung disease) were not associated with increased mortality.

Conclusion District hospitals supported primary care and shielded tertiary hospitals. Patients had high levels of comorbidities and similar clinical pictures to that reported
Strengths and limitations of this study

- The whole study population was included over a 4-month period at the height of the epidemic from eight district hospitals with few missing records.

- A comprehensive dataset on presentation, assessment, management and outcomes was captured.

- The size of the study population enabled identification of risk factors associated with mortality.

Data were dependent on the accuracy of medical records and clinical skills.

- District hospitals without family physicians may have different quality of care, which limits generalisability.

elsewhere. Most patients were treated as people under investigation. Mortality was comparable to similar settings and risk factors identified.

\section{INTRODUCTION}

COVID-19 is a global pandemic that has affected all regions of the world, although Africa has so far been less affected than predicted. ${ }^{1}$ Given the number of low- and middle-income countries, and relatively weak health systems, the pandemic is expected to significantly impact African communities. ${ }^{2}$ Within the African continent, South Africa has had the most reported cases and the Western Cape has been one of the leading hotspots. $^{13}$

Clinical findings among confirmed COVID-19 cases in China showed the most common complaints were fever $(83 \%)$, cough $(82 \%)$, difficulty breathing $(31 \%)$, fatigue and myalgia (11\%). ${ }^{4}$ Non-respiratory injury was identified by elevated levels of aspartate aminotransferase (20\%), creatinine (6\%) and creatine kinase $(15 \%) .^{5}$ 
Findings from another Chinese study showed that older patients and those with comorbidity had poorer clinical outcomes. ${ }^{5}$ Multimorbidity was also correlated with poorer clinical outcomes. ${ }^{6}$ Comorbidity with cardiopulmonary diseases was a particular concern, such as diabetes, hypertension, asthma and chronic obstructive pulmonary disease (COPD). In South Africa, there was also concern with regard to the large numbers of people with HIV, particularly those who were immunocompromised, due to no or inadequate antiretroviral treatment. South Africa has $20 \%$ of all people living with HIV in the world and this is accompanied by a high incidence of tuberculosis (TB). ${ }^{78}$ Patients with active TB or post-TB structural lung damage were also a concern in our context.

Most clinical research has focused on tertiary hospitals with high-care or intensive care units (ICU). Little is known, therefore, about the types of patients seen at district hospitals and their clinical course with the expertise and equipment available at this level of the health system and in this African context. In South Africa, district hospitals usually have $<150$ beds and are run by generalists with male, female, maternity and paediatrics wards as well as emergency centres (EC). They are the first referral point, particularly in remote and rural areas, for patients from primary care.

In Africa, primary or district hospitals do not provide intensive or critical care and have limited capacity for prolonged ventilation. At the same time, tertiary referral hospitals may not be able to receive patients if their ICU facilities are full or they are very distant. Elsewhere in Africa it has been suggested that district hospitals should focus more on the provision of oxygen therapy as a more valuable intervention than ventilation, as ventilation requires adequate equipment and expertise, with a risk of harm to the patient and transmission of the virus during intubation. ${ }^{9}$ Guidelines have also been put in place to determine which patients should be prioritised for ICU and which critically ill patients should be managed with oxygen and if necessary palliative care. ${ }^{10}$ In June 2020, Cape Town also opened field hospitals, which had the ability to manage patients with COVID-19 at a level of care similar to a district hospital. ${ }^{11}$

This study will describe the type of patients referred to district hospitals run by family physicians in the Western Cape and evaluate their presentation, clinical management and outcomes. This data will help to provide a more complete picture of how COVID-19 is affecting our population as the patient population seen at district hospitals is different to that seen at tertiary hospitals and African populations may differ from those in Europe, Asia or America.

The aim of this study, therefore, was to describe the characteristics, clinical management and outcomes of patients with COVID-19 presenting to district hospitals in the Western Cape from March 2020 to June 2020. The specific objectives were to describe the original source of referral, the presenting symptoms, the patients' demographics, the presence of comorbidities, the clinical assessment and management, the turnaround time (TOT) for laboratory results, the clinical outcomes and factors related to mortality, the length of stay and to compare district hospitals in rural health services (RHS) and metro health services (MHS).

\section{METHODS}

\section{Study design}

This was a descriptive observational cross-sectional study by means of a retrospective audit of medical records.

\section{Setting}

The Western Cape had 33 district hospitals: 28 small ( $<150$ beds), 3 medium (150-299 beds) and 2 large (300-600 beds). Small district hospitals in this study operated as generalist environments with family physicians as the most senior clinicians (one district hospital had an internal medicine physician running their inpatient COVID-19 ward). A family physician is a specialist in family medicine. In South Africa, family physicians are trained for the district hospital setting as well as primary care.

In terms of the continuum of care for COVID-19, these district hospitals received patients from the public sector primary care facilities in their catchment area. The private sector could also refer patients, without insurance, to the district hospitals. Patients in primary care, with more than mild symptoms, were referred for further management, although those requiring critical or intensive care could be referred directly to regional or tertiary hospitals. Therefore, the profile of patients seen and treated at district hospitals will be different to those referred to regional and tertiary hospitals as the capacity for critical care and intensive care was much less or nonexistent. These small district hospitals typically had ECs and re-organised their wards into 'hot' and 'cold' streams for COVID-19. Patients could be intubated and ventilated in the EC, prior to transfer, and there was not usually access to high flow oxygen, which was only installed in June in some hospitals. District hospitals could discharge patients to home, transfer them to a field hospital or to higher-level care.

\section{Study population and selection of participants}

The study engaged the Stellenbosch University Family Physician Research Network and the family physicians within that network who worked at small district hospitals in the province. Eight district hospitals, four from the MHS in Cape Town and three in the RHS, opted to take part. The study excluded medium-large metropolitan district hospitals that were organised along specialist departmental lines and which delivered a different package of care. George Regional Hospital was also included in the RHS, as its Department of Family Medicine offered district hospital services to the surrounding area and ran the EC. 
From these eight facilities, all patients who presented to the EC and who tested positive for COVID-19 were included between March and June 2020. There was no sampling or other exclusion criteria.

\section{Data collection}

Patients were identified from the laboratory results and their folders drawn from the records department. Data were extracted from the medical records using a standardised data collection tool by the family physicians at each hospital. Data were collected electronically using REDCap software on internet-connected devices available to the researchers. Overweight and obesity were defined as a body mass index $>25 \mathrm{~kg} / \mathrm{m}^{2}$. The South African Triage Scale was used by clinicians where red is for an immediate emergency, orange is very urgent, yellow is urgent and green is non-urgent. ${ }^{12}$ COVID-19 was classified according to clinical guidelines issued by the Western Cape Government: Health. ${ }^{13}$

The data collection tool was designed to collect data on the objectives listed above and the tool was validated by all the family physicians involved in the study prior to data collection. The tool was piloted by one district hospital prior to use.

\section{Data analysis}

Data were exported from REDCap to the Statistical Package for Social Sciences V.26. There was no missing data. Means with SD were used to describe continuous variables that were normally distributed and medians with IQRs to describe continuous data that were not normally distributed. Categorical data were analysed using frequencies and percentages.

Categorical variables were compared by Pearson's $\chi^{2}$ test. An independent T-test was used to compare continuous variables with binary variables if data were normally distributed and a Mann-Whitney $U$ test if data were not normally distributed. Analysis of variance was used to compare nominal variables with normally distributed numeric variables.

Univariate binary logistic regression was used to determine ORs for factors that might be associated with mortality (age, sex, comorbidities and location). Factors with a $p$ value $<0.1$ were then entered into a multiple variable forward stepwise binary logistic regression to determine which factors remained significantly associated with mortality.

\section{Patient and public involvement}

Patients and/or the public were not involved in the design, or conduct, or reporting, or dissemination plans of this research.

\section{RESULTS}

\section{Study sample}

Overall, 1376 patients were included in the study for this period and 1017 (73.9\%) were from the MHS and
$359(26.1 \%)$ from RHS. The mean age of patients was 46.3 years (SD 16.3 years) and patients were significantly older in the MHS compared with RHS (MHS 48.1 years (SD 16.1), RHS 41.4 years (SD 15.7), mean difference 6.73 years $(4.80-8.66), \mathrm{p}<0.001)$. Overall, there were 571 $(41.5 \%)$ males and $805(58.5 \%)$ females. There were significantly more females in the MHS sample than RHS ( $60.9 \%$ vs $51.8 \%$ female, $\mathrm{p}=0.003)$.

\section{Presentation and assessment}

Table 1 shows the characteristics of patients on arrival at the EC. Only $10 \%$ of patients were referred from public sector primary care facilities and the majority $(70.6 \%)$ were self-referred. Patients were significantly more likely to be referred from a primary care facility in the RHS as shown in table 1.

The most common symptoms were cough, shortness of breath, fever, body pains/myalgia and sore throat. The most common abnormal clinical signs were a raised respiratory rate, tachycardia, hyperglycaemia, decreased oxygen saturation and raised systolic blood pressure. The impression was that MHS patients were sicker (more dyspnoea, lower oxygen saturation, more confused) than those in the RHS at presentation and RHS patients had more symptoms from an earlier phase of the disease (sore throat, myalgia, nasal symptoms, cough).

Table 2 presents the comorbidities of patients. A third of patients had no known comorbidities. The most common comorbidities were hypertension, type 2 diabetes, overweight/obesity and HIV. Patients in the MHS had significantly more comorbidities than those in the RHS. On arrival the levels of prior control for many comorbidities was unknown, particularly in the rural areas. People with type 2 diabetes had the highest proportion that were uncontrolled.

Table 3 presents the initial assessment and final disposition from the EC. There was some mismatch between the initial triage and final assessment, with $53.1 \%$ of patients triaged as yellow and $17.1 \%$ of patients triaged as orange, being clinically assessed as mild COVID-19, and half $(49.1 \%)$ of all patients were assessed as mild. Patients from the RHS were significantly more likely to be assessed as mild and less likely to be admitted. Overall, $42.2 \%$ were discharged home from the EC, $47.4 \%$ admitted and only $6.2 \%$ transferred immediately to a higher level of care.

\section{Management in hospital}

Most patients were admitted as people under investigation and managed without a definitive diagnosis, as the TOT for the test result (median 3.0 days (IQR 2.0-5.0 days)) was longer than the length of stay (median 2.0 day (IQR 2.0-3.0)). There was no difference in the TOT between MHS and RHS (MHS median 3.0 days (IQR 3.0-4.0) and RHS 2.0 days (IQR 2.0-3.0), $\mathrm{p}=0.113$ ).

Half of all patients did not receive a chest radiograph in the EC or on admission $(695(50.5 \%))$ and this was significantly more likely in rural areas (MHS $41.9 \%$ vs RHS $74.7 \%, \mathrm{p}<0.001)$. The typical appearance was 
Table 1 Characteristics of patients on arrival at the EC

\begin{tabular}{|c|c|c|c|c|}
\hline & $\begin{array}{l}\text { All } \\
n=1376 \\
n(\%)\end{array}$ & $\begin{array}{l}\text { Metro } \\
n=1017 \\
n(\%)\end{array}$ & $\begin{array}{l}\text { Rural } \\
\mathrm{n}=359 \\
\mathrm{n}(\%)\end{array}$ & $P$ value \\
\hline \multicolumn{5}{|l|}{ Source of referral } \\
\hline Primary care facility & $137(10.0)$ & $69(6.8)$ & $68(18.9)$ & \multirow[t]{6}{*}{$<0.001$} \\
\hline Private general practice & $147(10.7)$ & $105(10.3)$ & $42(11.7)$ & \\
\hline Self-referral & $972(70.6)$ & $736(72.4)$ & $235(65.5)$ & \\
\hline Higher hospital & $5(0.4)$ & $5(0.5)$ & $0(0.0)$ & \\
\hline Other & $40(2.9)$ & $26(2.6)$ & $14(3.9)$ & \\
\hline Not known & $75(5.5)$ & $75(7.4)$ & $0(0.0)$ & \\
\hline \multicolumn{5}{|l|}{ Symptoms recorded on arrival } \\
\hline Sore throat & $332(24.1)$ & $186(18.3)$ & $146(40.7)$ & $<0.001$ \\
\hline Nasal symptoms & $93(6.8)$ & $61(6.0)$ & $32(8.9)$ & 0.059 \\
\hline Body pains/myalgia & $360(26.2)$ & $248(24.4)$ & $112(31.2)$ & 0.012 \\
\hline Fever & $441(32.0)$ & $302(29.7)$ & $139(38.7)$ & 0.002 \\
\hline Cough & $877(63.7)$ & $612(60.2)$ & $265(73.8)$ & $<0.001$ \\
\hline Shortness of breath & $717(52.1)$ & $545(53.6)$ & $172(47.9)$ & 0.062 \\
\hline Fatigue & $181(13.2)$ & $155(15.3)$ & $26(7.2)$ & $<0.001$ \\
\hline Loss smell & $64(4.7)$ & $43(4.2)$ & $21(5.8)$ & 0.211 \\
\hline Loss taste & $49(3.6)$ & $29(2.9)$ & $20(5.6)$ & 0.017 \\
\hline Diarrhoea & $82(6.0)$ & $70(6.9)$ & $12(3.3)$ & 0.015 \\
\hline Headache & $222(16.1)$ & $157(15.5)$ & $65(18.1)$ & 0.240 \\
\hline Other & $298(21.7)$ & $250(24.6)$ & $47(13.1)$ & $<0.001$ \\
\hline \multicolumn{5}{|l|}{ Observations recorded on arrival } \\
\hline Temperature $>37.5^{\circ} \mathrm{C}$ & $162(12.4)$ & $96(10.0)$ & $66(19.0)$ & $<0.001$ \\
\hline Respiratory rate $>18 / \mathrm{min}$ & $650(50.5)$ & $505(52.7)$ & $145(43.9)$ & 0.007 \\
\hline Pulse rate $>100 / \mathrm{min}$ & $646(47.9)$ & $491(49.3)$ & $154(43.8)$ & 0.013 \\
\hline Systolic BP $<90$ mm Hg & $31(2.6)$ & $28(3.2)$ & $3(1.0)$ & \multirow[t]{2}{*}{0.08} \\
\hline Systolic BP >140 mm Hg & $360(30.0)$ & $259(29.3)$ & $101(32.3)$ & \\
\hline Diastolic BP $<60 \mathrm{~mm} \mathrm{Hg}$ & $101(8.4)$ & $87(9.8)$ & $14(4.5)$ & \multirow[t]{2}{*}{0.008} \\
\hline Diastolic BP >90 mm Hg & $217(18.1)$ & $152(17.2)$ & $65(20.7)$ & \\
\hline Oxygen saturation $<95 \%$ & $557(41.9)$ & $439(44.8)$ & $118(33.8)$ & $<0.001$ \\
\hline Random blood glucose $<4.0 \mathrm{mmol} / \mathrm{L}$ & $22(2.5)$ & $15(2.1)$ & $7(3.9)$ & \multirow[t]{2}{*}{0.228} \\
\hline Random blood glucose $>7.8 \mathrm{mmol} / \mathrm{L}$ & $397(44.3)$ & $324(45.4)$ & $73(40.3)$ & \\
\hline Alert & $1264(91.9)$ & $921(90.6)$ & $342(95.3)$ & 0.034 \\
\hline Confused but responds to verbal commands & $82(6.0)$ & $69(6.8)$ & $13(3.6)$ & \\
\hline Unconscious but responds to pain & $10(0.7)$ & $7(0.7)$ & $3(0.8)$ & \\
\hline Unconscious with no response to pain & $6(0.4)$ & $5(0.5)$ & $1(0.3)$ & \\
\hline
\end{tabular}

$\mathrm{BP}$, blood pressure; EC, emergency centre.

bilateral changes in the lower or mid-zone, a ground glass appearance or consolidation. There were no major differences in the radiograph findings between MHS and RHS.

Table 4 presents the treatments for COVID-19. Only $40.6 \%$ received any form of oxygen therapy and very few were intubated $(0.8 \%)$. Those admitted were usually treated with oxygen, low molecular weight heparin (enoxaparin sodium) and antibiotics (ceftriaxone, azithromycin or co-amoxiclav) and far fewer patients were treated with proning or steroids. Proning was only used in $24 \%$ of those with severe or critical COVID-19.

Table 5 presents the final clinical outcomes. The overall mortality rate was $11.0 \%$ and $19.6 \%$ for those admitted. Mortality rose to $57.3 \%$ for those that were critically ill, $21.8 \%$ for severe cases, $7.5 \%$ for moderate cases and $1.8 \%$ for mild. Half of those admitted were discharged home 
Table 2 Comorbidities of patients with COVID-19

\begin{tabular}{|c|c|c|c|c|}
\hline & $\begin{array}{l}\text { All } \\
n=1376 \\
n(\%)\end{array}$ & $\begin{array}{l}\text { Metro } \\
\mathrm{n}=1017 \\
\mathrm{n}(\%)\end{array}$ & $\begin{array}{l}\text { Rural } \\
\mathrm{n}=359 \\
\mathrm{n}(\%)\end{array}$ & $P$ value \\
\hline \multicolumn{5}{|l|}{ Comorbidity } \\
\hline Overweight/Obesity & $269(19.5)$ & $208(20.5)$ & $61(17.0)$ & 0.153 \\
\hline Type 1 diabetes & $17(1.2)$ & $15(1.5)$ & $2(0.6)$ & 0.175 \\
\hline Type 2 diabetes & 347 (25.2) & $273(26.9)$ & $74(20.6)$ & 0.019 \\
\hline Hypercholesterolaemia & $83(6.0)$ & $77(7.6)$ & $6(1.7)$ & $<0.001$ \\
\hline Hypertension & $564(41.0)$ & $454(44.7)$ & $109(30.4)$ & $<0.001$ \\
\hline Cardiac failure & $58(4.2)$ & $51(5.0)$ & $7(1.9)$ & 0.013 \\
\hline Ischaemic heart disease & $25(1.8)$ & $24(2.4)$ & $1(0.3)$ & 0.011 \\
\hline Asthma & $67(4.9)$ & $52(5.1)$ & $15(4.2)$ & 0.477 \\
\hline COPD & $50(3.6)$ & $38(3.7)$ & $12(3.3)$ & 0.729 \\
\hline Post-TB lung damage & $12(0.9)$ & $8(0.8)$ & $4(1.1)$ & 0.567 \\
\hline HIV & 195 (14.2) & $156(15.4)$ & 39 (10.9) & 0.036 \\
\hline Active TB on treatment & $23(1.7)$ & $20(2.0)$ & $3(0.8)$ & 0.150 \\
\hline Previous TB & $49(3.6)$ & $40(3.9)$ & $9(2.5)$ & 0.209 \\
\hline Cancer on treatment & $10(0.7)$ & $9(0.9)$ & $1(0.3)$ & 0.244 \\
\hline Previous cancer & $2(0.1)$ & $2(0.2)$ & $0(0.0)$ & 0.400 \\
\hline Chronic kidney disease & $60(4.4)$ & $55(5.4)$ & $5(1.4)$ & 0.001 \\
\hline None & $450(32.7)$ & $276(27.2)$ & $174(48.5)$ & $<0.001$ \\
\hline Tobacco smoker & $95 / 621(15.3)$ & $80 / 490(16.3)$ & $15 / 131(11.5)$ & 0.168 \\
\hline \multicolumn{5}{|l|}{ Previous control of comorbidity } \\
\hline \multicolumn{5}{|l|}{ Diabetes $n=348$} \\
\hline Normal $\mathrm{HbA} 1 \mathrm{c}<7 \%$ & $32(9.2)$ & $30(10.8)$ & $2(2.9)$ & 0.002 \\
\hline Controlled HbA1c 7\%-8\% & $41(11.8)$ & $34(12.2)$ & $7(10.1)$ & \\
\hline Uncontrolled $\mathrm{HbA} 1 \mathrm{c}>8$ and $<10 \%$ & $68(19.5)$ & $56(20.1)$ & $12(17.4)$ & \\
\hline Very uncontrolled $\geq 10 \%$ & $131(37.6)$ & $110(39.4)$ & $21(30.4)$ & \\
\hline Unknown & $76(21.8)$ & $49(17.6)$ & $27(39.1)$ & \\
\hline \multicolumn{5}{|l|}{ Hypertension $n=446$} \\
\hline Well controlled & $165(37.0)$ & $150(41.6)$ & $14(16.7)$ & $<0.001$ \\
\hline Uncontrolled & $88(19.7)$ & $75(20.8)$ & $13(15.5)$ & \\
\hline Not known & $193(43.3)$ & $136(37.7)$ & $57(67.9)$ & \\
\hline \multicolumn{5}{|l|}{ Asthma $\mathrm{n}=72$} \\
\hline Well controlled & $23(31.9)$ & $21(51.2)$ & $2(6.5)$ & $<0.001$ \\
\hline Partly controlled & $10(13.9)$ & $6(14.6)$ & $4(12.9)$ & \\
\hline Uncontrolled & $5(6.9)$ & $5(12.2)$ & $0(0.0)$ & \\
\hline Unknown & $34(47.2)$ & $9(22.0)$ & $25(80.6)$ & \\
\hline \multicolumn{5}{|l|}{ COPD $n=56$} \\
\hline Mild & $7(12.5)$ & $5(15.6)$ & $2(8.3)$ & $<0.001$ \\
\hline Moderate & 11 (19.6) & $9(28.1)$ & $2(8.3)$ & \\
\hline Severe & 13 (23.2) & $12(37.5)$ & $1(4.2)$ & \\
\hline Unknown & $25(44.6)$ & $6(18.8)$ & 19 (79.2) & \\
\hline HIV $n=180$ & & & & \\
\hline
\end{tabular}


Table 2 Continued

\begin{tabular}{llllc} 
& $\begin{array}{l}\text { All } \\
\mathbf{n = 1 3 7 6} \\
\mathbf{n}(\%)\end{array}$ & $\begin{array}{l}\text { Metro } \\
\mathbf{n = 1 0 1 7} \\
\mathbf{n}(\%)\end{array}$ & $\begin{array}{l}\text { Rural } \\
\mathbf{n = 3 5 9} \\
\mathbf{n}(\%)\end{array}$ & P value \\
\hline Well controlled & $96(53.3)$ & $79(57.7)$ & $17(39.5)$ & 0.004 \\
Uncontrolled & $22(12.2)$ & $15(10.9)$ & $7(16.3)$ & \\
Unknown & $43(23.9)$ & $25(18.2)$ & $18(41.9)$ & \\
No ART & $16(8.9)$ & $16(11.7)$ & $0(0.0)$ & \\
New on ART & $3(1.7)$ & $2(1.5)$ & $1(2.3)$ & \\
\hline
\end{tabular}

ART, antiretroviral treatment; COPD, chronic obstructive pulmonary disease; HbA1c, haemoglobin A1c; TB, tuberculosis.

$(49.7 \%)$ and only $8.7 \%$ were transferred to a higher level of care and this was significantly more likely in the MHS $(\mathrm{p}<0.001)$. The MHS also made use of the field hospitals.

\section{Risk factors for mortality}

In the multiple variable analysis, increasing age, male sex, overweight/obesity, type 2 diabetes, chronic kidney disease, cardiac failure, HIV and treatment for cancer were all independently associated with a higher risk of death (table 6). Chronic respiratory conditions, such as asthma, COPD, post-TB lung damage and tobacco smoking were not associated with increased risk of mortality. Hypertension and hypercholesterolaemia were also not retained as risk factors in the multiple variable analysis. There was no difference in risk of mortality between the MHS and RHS. In addition, there was a significant relationship between poorer categories of diabetic control and mortality (OR 2.28 ( (95\% CI 1.25 to 4.16$), \mathrm{p}=0.007)$, but not with poor control of HIV (unsuppressed viral load) (OR 1.96 (95\% CI 0.62 to 6.23 ), $\mathrm{p}=0.253$ ). There was also no significant relationship with being on antiretroviral treatment (OR 0.879 (95\% CI 0.524 to 1.48 ), $\mathrm{p}=0.627$ ).

\section{DISCUSSION \\ Contribution of district hospitals to the health system response}

The majority of people with COVID-19 were self-referred and bypassed the gatekeeping role expected of public sector primary care facilities. Primary care facilities are often closed on weekends and afterhours making the

Table 3 Initial assessment and disposition from the emergency centre

\begin{tabular}{|c|c|c|c|c|}
\hline & $\begin{array}{l}\text { All } \\
n=1376 \\
n(\%)\end{array}$ & $\begin{array}{l}\text { Metro } \\
n=1017 \\
n(\%)\end{array}$ & $\begin{array}{l}\text { Rural } \\
\text { n=359 } \\
\text { n (\%) }\end{array}$ & P value \\
\hline \multicolumn{5}{|c|}{ Initial assessment in emergency centre } \\
\hline Triage green & $455(33.1)$ & $267(26.4)$ & $188(53.1)$ & \multirow[t]{2}{*}{$<0.001$} \\
\hline Triage yellow & $292(21.3)$ & $200(19.7)$ & $91(25.7)$ & \\
\hline Mild COVID & $676(49.1)$ & $443(43.6)$ & $232(64.6)$ & \multirow[t]{4}{*}{$<0.001$} \\
\hline Moderate COVID & $252(18.3)$ & $191(18.8)$ & $61(17.0)$ & \\
\hline Severe COVID & $335(24.3)$ & $303(29.8)$ & $32(8.9)$ & \\
\hline Critical COVID & $82(6.0)$ & $72(7.1)$ & $10(2.8)$ & \\
\hline \multicolumn{5}{|c|}{ Disposition from emergency centre } \\
\hline Transferred to higher level & $85(6.2)$ & $66(6.5)$ & $19(5.3)$ & \multirow{6}{*}{$<0.001$} \\
\hline Transferred to assisted isolation & $12(0.9)$ & $2(0.2)$ & $10(2.8)$ & \\
\hline Transferred to field hospital & $20(1.5)$ & $19(1.9)$ & $1(0.3)$ & \\
\hline Admitted to district hospital & $652(47.4)$ & $531(52.2)$ & $121(33.7)$ & \\
\hline Died & $13(0.9)$ & $10(1.0)$ & $3(0.8)$ & \\
\hline Other & $13(0.9)$ & $11(1.1)$ & $2(0.6)$ & \\
\hline
\end{tabular}


Table 4 Treatment received at the district hospital

\begin{tabular}{lccccc}
\hline & $\begin{array}{l}\text { All } \\
\mathbf{n = 1 3 7 6} \\
\mathbf{n}(\%)\end{array}$ & $\begin{array}{l}\text { Admitted } \\
\mathbf{n = 6 2 5} \\
\mathbf{n}(\%)\end{array}$ & $\begin{array}{l}\text { Metro } \\
\mathbf{n = 1 0 1 7} \\
\mathbf{n}(\%)\end{array}$ & $\begin{array}{l}\text { Rural } \\
\mathbf{n = 3 5 9} \\
\mathbf{n}(\%)\end{array}$ & P value \\
\hline Any form of oxygen & $558(40.6)$ & $461(70.7)$ & $452(44.5)$ & $106(29.5)$ & $<0.001$ \\
\hline Oxygen by nasal prongs 1-4 L/min & $265(19.3)$ & $212(32.5)$ & $226(22.2)$ & $39(10.9)$ & $<0.001$ \\
\hline Oxygen by facemask 6-10 L/min & $240(17.4)$ & $212(32.5)$ & $207(20.4)$ & $33(9.2)$ & $<0.001$ \\
\hline Oxygen with non-rebreather reservoir bag 10-15 L/min & $177(12.9)$ & $130(19.9)$ & $136(13.4)$ & $41(11.4)$ & 0.339 \\
\hline Oxygen high flow >15 L/min & $12(0.9)$ & $8(1.2)$ & $6(0.6)$ & $6(1.7)$ & 0.058 \\
\hline Intubation and ventilation & $11(0.8)$ & $3(0.5)$ & $5(0.5)$ & $6(1.7)$ & 0.031 \\
\hline Proning & $142(10.3)$ & $105(16.1)$ & $135(13.3)$ & $7(1.9)$ & $<0.001$ \\
\hline Enoxaparin sodium any & $583(42.4)$ & $503(77.1)$ & $504(49.6)$ & $79(22.0)$ & $<0.001$ \\
\hline Enoxaparin sodium 40 mg/day & $308(22.4)$ & $272(41.7)$ & $250(24.6)$ & $58(16.2)$ & 0.001 \\
\hline Enoxaparin sodium 1 mg/kg daily & $218(15.8)$ & $191(29.3)$ & $203(20.0)$ & $15(4.2)$ & $<0.001$ \\
\hline Enoxaparin sodium 1 mg/kg two times per day & $74(5.4)$ & $57(8.7)$ & $67(6.6)$ & $7(1.9)$ & 0.001 \\
\hline Ceftriaxone & $556(40.4)$ & $460(70.6)$ & $501(49.3)$ & $55(15.3)$ & $<0.001$ \\
\hline Azithromycin & $541(39.3)$ & $427(65.5)$ & $440(43.3)$ & $101(28.1)$ & $<0.001$ \\
\hline Co-amoxiclav & $166(12.1)$ & $106(16.3)$ & $80(7.9)$ & $86(24.0)$ & $<0.001$ \\
\hline Any steroid & $253(18.4)$ & $183(28.1)$ & $196(19.3)$ & $57(15.9)$ & 0.151 \\
\hline Dexamethasone & $111(8.1)$ & $78(12.0)$ & $83(8.2)$ & $28(7.8)$ & 0.825 \\
\hline Hydrocortisone & $15(1.1)$ & $12(1.8)$ & $13(1.3)$ & $2(0.6)$ & 0.257 \\
\hline Prednisone & $131(9.5)$ & $97(14.9)$ & $102(10.0)$ & $29(8.1)$ & 0.277 \\
\hline
\end{tabular}

district hospital EC the next available point of access. Primary care facilities also de-escalated during the epidemic and people were turned away or advised to stay away as much as possible,${ }^{14}$ while there was no restrictions on access to district hospitals. In some areas, primary care facilities temporarily closed when staff were infected. Although primary care facilities could test, the district hospitals had larger and more visible testing centres. This, in addition to fear of more severe disease and more trust in hospital-based services, may have led people to present directly to the hospital. In rural areas, where the hospital was more geographically distant, more people entered the system via primary care facilities. District hospitals, therefore, played an important role in primary care during the epidemic and this is reflected in the findings that $49 \%$ of patients seen had mild COVID-19\% and $42 \%$ were immediately discharged home from the EC.
This also reflects the need to improve access to primary care in South Africa. ${ }^{15}$

District hospitals reduced pressure on tertiary hospitals with ICU and critical care beds particularly for those with moderate and severe COVID-19. Of those with moderate COVID-19, only $9 \%$ were transferred to tertiary hospitals and mortality was $7.5 \%$. For those with severe disease, $17 \%$ were transferred and mortality was $22 \%$, which compares favourably with reports from high-income settings. ${ }^{16}$ District hospitals were unable to manage critically ill patients, as they did not have ICU or critical care facilities.

The introduction of field hospitals, such as at the Cape Town International Convention Centre ${ }^{17}$ also took pressure off acute hospitals and $13.5 \%$ of patients were transferred for ongoing care thus creating additional capacity at the district hospital. The first field hospital only

Table 5 Clinical outcomes at the district hospitals

\begin{tabular}{|c|c|c|c|c|c|c|c|c|}
\hline Clinical outcome & $\begin{array}{l}\text { Admitted } \\
\mathrm{n}=652 \\
\mathrm{n}(\%)\end{array}$ & $\begin{array}{l}\text { All } \\
n=1376 \\
n(\%)\end{array}$ & $\begin{array}{l}\text { Metro } \\
n=1017 \\
n(\%)\end{array}$ & $\begin{array}{l}\text { Rural } \\
\mathrm{n}=359 \\
\mathrm{n}(\%) \\
\end{array}$ & $\begin{array}{l}\text { Mild } \\
\text { n=676 } \\
\text { n (\%) }\end{array}$ & $\begin{array}{l}\text { Moderate } \\
\mathrm{n}=252 \\
\mathrm{n}(\%)\end{array}$ & $\begin{array}{l}\text { Severe } \\
n=335 \\
n(\%)\end{array}$ & $\begin{array}{l}\text { Critical } \\
\mathrm{n}=82 \\
\mathrm{n}(\%)\end{array}$ \\
\hline Died & $128(19.6)$ & $151(11.0)$ & $118(11.6)$ & $33(9.2)$ & $12(1.8)$ & $19(7.5)$ & $73(21.8)$ & $47(57.3)$ \\
\hline Discharged home & $324(49.7)$ & $831(60.4)$ & $577(56.8)$ & $253(70.5)$ & $525(77.7)$ & $147(58.3)$ & $130(38.8)$ & $7(8.5)$ \\
\hline Transferred tertiary hospital & $57(8.7)$ & $118(8.6)$ & $115(11.3)$ & $3(0.8)$ & $20(3.0)$ & $23(9.1)$ & 55 (16.4) & $20(24.4)$ \\
\hline Transferred assisted isolation & $30(4.6)$ & $47(3.4)$ & $20(2.0)$ & $27(7.5)$ & $26(3.8)$ & $11(4.4)$ & $3(0.9)$ & $0(0.0)$ \\
\hline
\end{tabular}




\begin{tabular}{|c|c|c|}
\hline Variable & $\begin{array}{l}\text { Unadjusted OR } \\
(95 \% \mathrm{Cl})\end{array}$ & $P$ value \\
\hline Cancer on treatment & 12.63 (3.5 to 42.3 ) & $<0.001$ \\
\hline Chronic kidney disease & 10.65 (6.21 to 18.28$)$ & $<0.001$ \\
\hline Cancer previous & $8.16(0.51$ to 131.14$)$ & 0.138 \\
\hline Cardiac failure & 5.63 (3.21 to 9.87) & $<0.001$ \\
\hline Post-TB SLD & 4.14 (1.23 to 13.9$)$ & 0.022 \\
\hline Hypertension & 3.95 (2.73 to 5.70$)$ & $<0.001$ \\
\hline Type 2 diabetes & 3.1 (2.2 to 4.3$)$ & $<0.001$ \\
\hline TB on treatment & 2.94 (1.14 to 7.57$)$ & 0.026 \\
\hline Ischaemic heart disease & 2.06 (0.76 to 5.58$)$ & 0.154 \\
\hline Hypercholesterolaemia & 1.88 (1.04 to 3.37$)$ & 0.035 \\
\hline TB previous & 1.88 (0.89 to 3.95$)$ & 0.097 \\
\hline Overweight/Obese & 1.69 (1.15 to 2.49$)$ & 0.007 \\
\hline HIV & 1.67 (1.09 to 2.56$)$ & 0.019 \\
\hline Male sex & 1.63 (1.16 to 2.30$)$ & 0.005 \\
\hline COPD & 1.34 (0.59 to 3.03 ) & 0.487 \\
\hline Asthma & 1.11 (0.52 to 2.36$)$ & 0.795 \\
\hline Type 1 diabetes & $1.08(0.24$ to 4.78$)$ & 0.916 \\
\hline Increasing age & 1.06 (1.05 to 1.07$)$ & $<0.001$ \\
\hline Turnaround time & 1.02 (0.99 to 1.06$)$ & 0.216 \\
\hline Tobacco smoking & 1.01 (0.46 to 2.21$)$ & 0.986 \\
\hline Length of admission & 0.97 (0.93 to 1.02$)$ & 0.219 \\
\hline $\begin{array}{l}\text { Rural versus metro } \\
\text { services }\end{array}$ & 0.77 (0.51 to 1.16$)$ & 0.208 \\
\hline No comorbidities & 0.17 (0.09 to 0.30$)$ & $<0.001$ \\
\hline Variable & $\begin{array}{l}\text { Adjusted } \\
\text { OR (95\% Cl) }\end{array}$ & $P$ value \\
\hline Cancer on treatment & 7.45 (1.87 to 29.89$)$ & 0.004 \\
\hline Chronic kidney disease & 5.16 (2.82 to 9.43$)$ & $<0.001$ \\
\hline HIV & 3.41 (2.06 to 5.65$)$ & $<0.001$ \\
\hline Cardiac failure & 2.85 (1.52 to 5.35$)$ & 0.001 \\
\hline Male sex & 2.02 (1.37 to 2.98$)$ & $<0.001$ \\
\hline Type 2 diabetes & 1.84 (1.24 to 2.73 ) & 0.002 \\
\hline Overweight/Obese & 1.58 (1.02 to 2.46$)$ & 0.04 \\
\hline Increasing age & 1.06 (1.04 to 1.07$)$ & $<0.001$ \\
\hline
\end{tabular}

COPD, chronic obstructive pulmonary disease; SLD, structural lung damage; TB, tuberculosis.

opened in June 2020, the last month of this study period. At the field hospital, care might include management of comorbidities, palliative care or further recovery prior to discharge home. ${ }^{17}$

The differences between RHS and MHS appeared to represent differences in the type of patients and geographic access rather than health services. RHS appeared to have younger patients, more often referred by local primary care facilities, with fewer comorbidities and less severe disease, which translated into lower mortality and better outcomes. In the Western Cape, the rural district hospitals had good infrastructure, equipment and competent clinical teams led by family physicians.

No other studies were found reporting on district hospitals from low-income and middle-income countries. The few studies from the UK reporting on district hospitals are not comparable as these hospitals offer specialist services and serve a different type of population. ${ }^{18}$ District or primary hospitals in our setting are small, often rural or remote, and led by generalists or family physicians. These types of hospitals are rare in high-income countries, but an important part of African health systems. Although district hospitals in the Western Cape are generally well resourced and led by family physicians, in other parts of Africa these hospitals may have significant skills, equipment and infrastructure gaps. ${ }^{19}$ African populations are also younger and have a different profile of comorbidities with communicable diseases more prominent (such as HIV, TB and malaria). Poverty is also a major issue that impacts on access to healthcare as well as food security and malnutrition. ${ }^{19}$ It is therefore important to evaluate how people with COVID-19 are managed and what their outcomes are at this level of African health systems.

\section{Management of COVID-19 at district hospitals}

Patients presented with the typical symptoms of COVID-19 that have also been reported elsewhere in Africa. ${ }^{20}$ Fever, however, was only found in $12 \%$ of patients and many patients had hyperglycaemia and high blood pressure, reflecting underlying comorbidities. Family physicians reported that the procedures to use infrared thermometers to triage patients may not have resulted in accurate measurements and therefore fever may be underobserved. ${ }^{21}$ Not all patients had a body mass index measured and overweight/obesity was probably under-reported.

As the median TOT for COVID-19 tests was longer than the median length of admission, most patients were managed as people under investigation, who were presumed to have COVID-19. The laboratory capacity and TOT for COVID-19 tests has been labelled 'the Achilles heel' of the local response to the pandemic. ${ }^{22}$ The in-hospital TOT improved once the criteria for community testing were changed, from all people with relevant symptoms to only those over 55 years or with comorbidities or with more than mild disease. ${ }^{23}$

Antibiotics were presumably given as the diagnosis was not confirmed in the majority of patients and the patient were treated as a community-acquired pneumonia with COVID-19 as part of the differential diagnosis. Steroids were only given in $28 \%$ of patients, but the evidence of their effectiveness were only announced in June 2020, ${ }^{24}$ which was the last month of this study period.

Basic imaging with a chest radiograph was only performed in half the patients, which mirrors the large number of mild cases who did not require imaging. All district hospitals had access to radiography, although not always 24 hours a day and in some cases the clinician may have judged that management of the patient would 
not be changed. In addition, radiography might have been avoided in order to reduce exposure of people to COVID-19 as patients would have to traverse the hospital to access the radiography unit if a mobile radiograph was not available. Not all critically ill received a radiograph and this might be because they died before a radiograph could be taken or were transferred. Patients were referred on the basis of the clinical picture and a radiograph was not essential.

\section{Clinical outcomes at district hospitals}

Overall in-hospital mortality for COVID-19 was $11 \%$ and rose to $20 \%$ in those admitted. Mortality was significantly higher in MHS facilities compared with RHS and this most likely reflects the higher severity of patients, rather than differences in management of patients. Mortality rates reported from a field hospital in Ethiopia were much lower $(5.3 \%)$ despite a similar profile of COVID-19 severity in those seen. ${ }^{25}$ This may be explained by much lower levels of comorbidity. For example, no HIV or TB was reported and diabetes was found in $14 \%$ as opposed to $25 \%$ of patients.

A local population cohort study also found an association between people living with HIV and mortality from COVID-19 and no clear association with viraemia or immunosuppression. ${ }^{26}$ However, in district hospitals we found no association with previous or current TB infection and mortality from COVID-19, while the population cohort study found a twofold increase. The population study may have overestimated risks as routine data did not include all comorbidities and these patients were more likely to be followed up and diagnosed with COVID-19. Other respiratory conditions such as asthma, COPD and post-TB structural lung disease were also not associated with increased mortality. This could suggest that immunological factors were maybe more important than pulmonary factors in determining risk of death. Other conditions with impaired or altered immunity were also associated with mortality, such as type 2 diabetes and people receiving treatment for cancer.

The combination of increasing age, overweight/obesity, type 2 diabetes, chronic kidney disease and cardiac failure as independent risk factors is important as one in two South Africans over the age of 45 years have prediabetes or diabetes. ${ }^{27}$ Increasing age, obesity and chronic kidney disease were also identified as key risk factors in the Democratic Republic of Congo ${ }^{28}$ and diabetes in Ethiopia. The importance of non-communicable diseases, such as diabetes, was brought into the public spotlight by COVID-19 as previously the focus of attention was on HIV and TB. The level of control of diabetes was also directly related to risk of mortality, which emphasised the need to improve self-management and treatment, particularly as $57 \%$ had a history of poor control on admission. The absence of electronic medical records and an integrated health information system explains why hospitals could not obtain information on prior control of chronic diseases, particularly in the RHS. The continuity of care for type 2 diabetes was also disrupted by the de-escalation of services and most forms of patient education and counselling were stopped. There is a need to innovate new ways of managing and empowering people with diabetes while reducing their risk of exposure to COVID-19 at health facilities and support groups.

All results were dependent on the completeness and accuracy of medical records. For example, clinicians may not have recorded all the symptoms experienced by the patients. Family physicians did not report a problem with missing medical records. It would have been helpful to record the antiretroviral treatment regimen in patients with HIV and to investigate any association between mortality and exposure to different combinations of medications. No data were collected on laboratory results such as full blood count, urea or creatinine or on the time between onset of symptoms and treatment, and this might have been useful to investigate the relationship with clinical outcomes. It was not possible to determine the outcomes of patients that were discharged from the EC with mild disease and it is possible that some were re-admitted to other hospitals. None of the family physicians collecting data reported that patients in the study were re-admissions.

These hospitals all had family physicians heading their clinical teams and it is possible that they had a higher quality of care than the hospitals that are still without them. The Western Cape also has better infrastructure and a stronger health system than many other provinces and the quality of care is likely to be lower in other parts of South Africa.

\section{CONCLUSIONS}

District hospitals provided an essential primary care service for many patients with mild symptoms of COVID-19 during the epidemic. This also represented a deficiency in access to and utilisation of primary care. District hospitals successfully treated a large number of people with moderate-to-severe COVID-19 who did not need ventilation and took pressure off higher-level facilities. Limited laboratory capacity meant that most patients were treated as people under investigation without a definitive diagnosis. The clinical picture was similar to that reported elsewhere. Mortality at this level of care was associated with increasing age, male sex, HIV, type 2 diabetes, overweight/obesity, cardiac failure, chronic kidney disease and treatment for cancer, but not with hypertension, TB, asthma, COPD or post-TB lung damage. Patients in the MHS were more numerous, had more comorbidity and more severe COVID-19 disease than in the RHS.

\section{Author affiliations}

${ }^{1}$ Family Medicine and Primary Care, University of Stellenbosch, Stellenbosch, Western Cape, South Africa

${ }^{2}$ Metro Health Services, Western Cape Provincial Government, Cape Town, South Africa

${ }^{3}$ Rural Health Services, Western Cape Provincial Government, Cape Town, South Africa 
${ }^{4}$ Family Medicine, University of Cape Town, Cape Town, Western Cape, South Africa ${ }^{5}$ Internal Medicine, University of Stellenbosch, Stellenbosch, Western Cape, South Africa

\section{Twitter Adeloye Adeniji @Adeniji charles Ade}

Contributors RJM and MP-V conceptualised the study. All authors approved the study proposal. MP-V, AH and HM collected data at Eerste River Hospital; AL and KS collected data at Helderberg Hospital; AU and RC collected data at Wesfleur Hospital; LR collected data at False Bay Hospital; LJ collected data at George Hospital; LH and PK collected data at Knysna Hospital; LE and BW collected data at Stellenbosch Hospital; AA and KD collected data at Ceres Hospital. RJM analysed the data. All authors gave feedback on their interpretation of the results. RJM and MP-V wrote the draft manuscript. All authors gave feedback on the manuscript and approved the final version.

Funding The authors have not declared a specific grant for this research from any funding agency in the public, commercial or not-for-profit sectors.

Competing interests None declared.

Patient consent for publication Not required.

Ethics approval The study was approved by the Health Research Ethics Committee at Stellenbosch University (N20/06/032_COVID-19) who granted a waiver of informed consent for collection on anonymised data from medical records. Study permission was obtained from the Provincial Government of the Western Cape to conduct the study.

Provenance and peer review Not commissioned; externally peer reviewed.

Data availability statement Data are available on reasonable request. Deidentified participant data are available on reasonable request from the first author Professor Robert Mash orcid.org/0000-0001-7373-0774.

Open access This is an open access article distributed in accordance with the Creative Commons Attribution Non Commercial (CC BY-NC 4.0) license, which permits others to distribute, remix, adapt, build upon this work non-commercially, and license their derivative works on different terms, provided the original work is properly cited, appropriate credit is given, any changes made indicated, and the use is non-commercial. See: http://creativecommons.org/licenses/by-nc/4.0/.

\section{ORCID iD}

Robert James Mash http://orcid.org/0000-0001-7373-0774

\section{REFERENCES}

1 COVID-19 coronavirus pandemic [Internet], 2020. Available: https:// www.worldometers.info/coronavirus/ [Accessed 06 Jun 2020].

2 Lone SA, Ahmad A. COVID-19 pandemic - an African perspective. Emerg Microbes Infect 2020;9:1300-8.

3 Coronavirus in South Africa [Internet], 2020. Available: https:// mediahack.co.za/datastories/coronavirus/dashboard/ [Accessed cited 2020 Jun 6].

4 Chen N, Zhou M, Dong X, et al. Epidemiological and clinical characteristics of 99 cases of 2019 novel coronavirus pneumonia in Wuhan, China: a descriptive study. Lancet 2020;395:507-13. doi:10.1016/S0140-6736(20)30211-7

5 Zhao X-Y, Xu X-X, Yin H-S, et al. Clinical characteristics of patients with 2019 coronavirus disease in a non-Wuhan area of Hubei Province, China: a retrospective study. BMC Infect Dis 2020;20:311.

6 Guan W-J, Ni Z-Y, Hu Y, et al. Clinical characteristics of coronavirus disease 2019 in China. N Engl J Med 2020;382:1708-20. doi:10.1056/NEJMoa2002032

7 Allinder S. The World's Largest HIV Epidemic in Crisis: HIV in South Africa | Center for Strategic and International Studies [Internet]. Centre for Strategic and International Studies, 2019. Available: https://www.csis.org/analysis/worlds-largest-hiv-epidemic-crisis-hivsouth-africa\# [Accessed 05 Nov 200].
8 Massyn N, Barron P, Day C. District Health Barometer 2018/19 [Internet]. Cape Town, 2020. Available: https://www.hst.org.za/ publications/Pages/DISTRICT-HEALTH-BAROMETER-201819.aspx [Accessed 05 Nov 2020].

9 Madzimbamuto FD. Ventilators are not the answer in Africa. Afr J Prm Health Care Fam Med. 2020;12:a2517.

10 Government of Western Cape. Health. Western Cape critical care triage tool. Available: https://www.westerncape.gov.za/assets/ departments/health/COVID-19/western_cape_critical_care_triage tool_version_1.2_14th_may.pdf [Accessed 18 Dec 2020].

11 First patients admitted to special Covid-19 field hospital in Cape Town. Available: https://www.timeslive.co.za/news/south-africa/ 2020-06-08-first-patients-admitted-to-special-covid-19-fieldhospital-in-cape-town/ [Accessed 11 Jun 2020].

12 The South African Triage Scale (SATS) [Internet]. Available: https:// emssa.org.za/special-interest-groups/the-south-african-triage-scalesats/ [Accessed 05 Nov 2020].

13 COVID-19 Health Worker Resources [Internet], 2020. Available: https://knowledgetranslation.co.za/resources/covid-19-hwresources/ [Accessed 06 Jun 2020].

14 Mash R, Goliath C, Perez G. Re-Organising primary health care to respond to the coronavirus epidemic in Cape town, South Africa. Afr J Prim Health Care Fam Med 2020;12:4.

15 Bresick G, von Pressentin KB, Mash R. Evaluating the performance of South African primary care: a cross-sectional descriptive survey. South African Fam Pract 2019;61:109-16.

16 Santorelli G, Sheldon T, West J, et al. COVID-19 in-patient hospital mortality by ethnicity. Wellcome Open Res 2020;5:86.

17 Reid S, Ras T, Von Pressentin K. The Cape Town International Convention Centre from the inside: The family physicians' view of the 'Hospital of Hope'. Afr J Prim Health Care Fam Med 2020;12:4.

18 Knights H, Mayor N, Millar K, et al. Characteristics and outcomes of patients with COVID-19 at a district general Hospital in Surrey, UK. Clin Med 2020;20:e148-53.

19 Agyepong IA, Sewankambo N, Binagwaho A, et al. The path to longer and healthier lives for all Africans by 2030: the Lancet Commission on the future of health in sub-Saharan Africa. Lancet 2018;390:2803-59. doi:10.1016/S0140-6736(17)31509-X

20 Olumade TJ, Uzairue LI. Clinical characteristics of 4490 COVID-19 patients in Africa: a meta-analysis. medRxiv 2020:2020.10.20.20215905.

21 Chen $\mathrm{H}-\mathrm{Y}$, Chen A, Chen C. Investigation of the impact of infrared sensors on core body temperature monitoring by comparing measurement sites. Sensors 2020;20:2885.

22 Porter JD, Mash R, Preiser W. Turnaround times - the Achilles' heel of community screening and testing in Cape Town, South Africa: A short report. Afr J Prim Health Care Fam Med 2020;12:e1-e3. doi:10.4102/phcfm.v12i1.2624

23 David N, Mash R. Community-Based screening and testing for coronavirus in Cape town, South Africa: short report. Afr J Prim Health Care Fam Med 2020;12:3.

24 The RECOVERY Collaborative Group. Dexamethasone in hospitalized patients with Covid-19 - preliminary report. N Engl J Med Overseas Ed 2020:NEJMoa2021436.

25 Leulseged TW, Hassen IS, Maru EH. Characteristics and outcome profile of hospitalized African COVID-19 patients: the Ethiopian context. medRxiv2020:2020.10.27.20220640.

26 Boulle A, Davies M-A, Hussey H, et al. Risk factors for COVID-19 death in a population cohort study from the Western Cape Province, South Africa. Clin Infect Dis 2020:ciaa1198. doi:10.1093/cid/ ciaa1198

27 The Society for Endocrinology M and D of SAT 2 DGEC. SEMDSA guidelines for the management of type 2 diabetes. Journal of Endocrinology, Metabolism and Diabetes of South Africa 2017:22:S1-196.

28 Nachega JB, Ishoso DK, Otokoye JO, et al. Clinical characteristics and outcomes of patients hospitalized for COVID-19 in Africa: early insights from the Democratic Republic of the Congo. Am J Trop Med Hyg 2020;103:2419-28. doi:10.4269/ajtmh.20-1240 